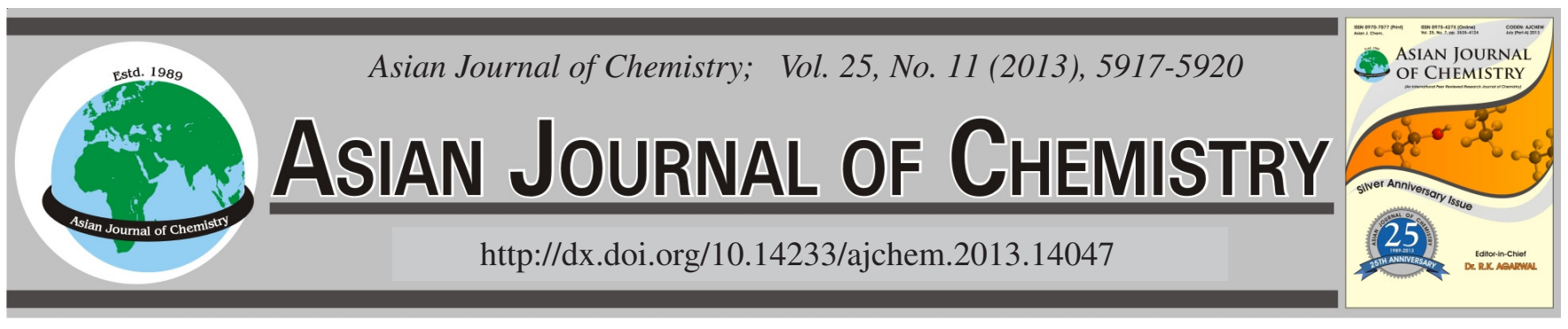

\title{
Degradation of Polycyclic Aromatic Hydrocarbons Contamination in Groundwater by Sodium Percarbonate Oxidation
}

\author{
Yue-Hua Zhang ${ }^{1}$, Yu-Gang Sun $^{1}$, Li-Hong YuE ${ }^{2}$ and Chang-Hong Guo ${ }^{1, *}$
}

${ }^{1}$ Key Laboratory of Molecular Cytogenetic and Genetic Breeding of Heilongjiang Province, College of Life Science and Technology, Harbin Normal University, Harbin, P.R. China

${ }^{2}$ Institute of Applied Microbiology of College of Life Science, Jiamusi University, Jiamusi, P.R. China

*Corresponding author: E-mail: kaku3008@163.com

(Received: 8 June 2012;

Accepted: 18 April 2013)

AJC-13367

\begin{abstract}
Sodium percarbonate has been used to oxidize a wide range variety of organic and inorganic compounds in water under multiple conditions of environment of contamination in groundwater. Sodium percarbonate is effective showed over a wide $\mathrm{pH}$ ranges. Even though the theoretical dosage of $[\mathrm{PAHs}] /\left[2 \mathrm{Na}_{2} \mathrm{CO}_{3} \cdot 3 \mathrm{H}_{2} \mathrm{O}_{2}\right]$ even down to 0.4 for complete degradation of polycyclic aromatic hydrocarbons (PAHs), it still needed, at least, $3 \mathrm{~mol}$ of $\left[2 \mathrm{Na}_{2} \mathrm{CO}_{3} \cdot 3 \mathrm{H}_{2} \mathrm{O}_{2}\right]$ to degradation this chemical dosage. This indicates that oxidation intermediates competed sodium percarbonate molecules with the parent polycyclic aromatic hydrocarbons. The primary pH has no obviously efficacy on polycyclic aromatic hydrocarbons decompose, for hydrogen-ions were conformation during the degradation of polycyclic aromatic hydrocarbons.
\end{abstract}

Key Words: Sodium Percarbonate, Degradation, Polycyclic aromatic hydrocarbons, Contamination.

\section{INTRODUCTION}

Limited to high-cost on-site stabilization or excavation followed by off-site incineration. In situ remediation of contaminated soils is considered more cost-efficient than on-site and off-site treatment, but it depends on the quantity and location of the soil to be treated ${ }^{1}$. Advanced oxidation processes (e.g. modified Fenton reactions) and biodegradation are promising in situ remediation techniques. The biodegradation of highmolecular-weight polycyclic aromatic hydrocarbons is slow ${ }^{2}$ and bioavailability of polycyclic aromatic hydrocarbons in contaminated soil is limited ${ }^{3}$. Therefore these compounds have serious attention to regulatory levels. Polycyclic aromatic hydrocarbons usually occur in the subsurface as local zones of residual zones concentration or occasionally exist as monomer products ${ }^{4}$. Because of polycyclic aromatic hydrocarbons in nature of low solubility in fluid and exist in dense non-aqueous phase liquids persist in aquifers, especially provide a stable supply source of contaminants 5 . Chemical oxidation of polycyclic aromatic hydrocarbon employed in studies included ozone $\left(\mathrm{O}_{3}\right)$, in Fenton process, hydroxyl radicals are generated by the reaction of hydrogen peroxide and ferrous ions to oxidize organic compounds. When using the Fenton's reagent for the treatment of contaminated soil and groundwater, reaction $\mathrm{pH}$ needs to be controlled between from 2 to 4 . Therefore, this technology is difficult to apply in the field of in situ pretreatment ${ }^{6}$. The chemical oxidation of toxic and hazardous organic pollutants such as polycyclic aromatic hydrocarbons is often carried out by using single oxidants such as chlorine or ozone. However, this decomposition may be difficult if these pollutants are present at high concentrations or if they are especially refractory to the oxidants?

Sodium percarbonate has an active available oxygen content which is equivalent to $27.5 \% \mathrm{H}_{2} \mathrm{O}_{2}$. It breaks down to oxygen, water and sodium carbonate upon decomposition. Sodium percarbonate offers many functional benefits as liquid hydrogen peroxide. It dissolves into water to release oxygen. In comparison to Fenton's reagent, sodium percarbonate $\left(2 \mathrm{Na}_{2} \mathrm{CO}_{3} \cdot 3 \mathrm{H}_{2} \mathrm{O}_{2}\right)$ can effectively oxidize many water impurities and is also effective over a wide $\mathrm{pH}$ range. Reaction of $2 \mathrm{Na}_{2} \mathrm{CO}_{3} \cdot 3 \mathrm{H}_{2} \mathrm{O}_{2}$ with organic compounds produces carbon dioxide, water and a small amount of sodium carbonate, which is naturally present in soils. Therefore, the production of carbon dioxide, water and a small amount of sodium carbonate is not of environmental concern. In addition, $2 \mathrm{Na}_{2} \mathrm{CO}_{3} \cdot 3 \mathrm{H}_{2} \mathrm{O}_{2}$ is non-toxic to microbes, making it compatible with bioremediation, so no hazards environmental due to it breaks down to oxygen, water and sodium carbonate (soda ash) in environmental $^{4,7}$. There are many studies focusing on polycyclic aromatic hydrocarbons oxidation, but no literature is available 
reporting on the optimum dosage of $2 \mathrm{Na}_{2} \mathrm{CO}_{3} \cdot 3 \mathrm{H}_{2} \mathrm{O}_{2}$. Therefore, this study was to investigate he effects of the molar ratio and $\mathrm{pH}$ on polycyclic aromatic hydrocarbons oxidation in aqueous phase. In addition, the extent of dechlorination is also reported.

\section{EXPERIMENTAL}

Aqueous solution of polycyclic aromatic hydrocarbons $(7 \mathrm{~mL})$ was extracted with chloroform twice $(30 \mathrm{~mL}$ each times) and the above layers were collected, dried with $\mathrm{Na}_{2} \mathrm{SO}_{4}$ and evaporated to $1 \mathrm{~mL}$ for the determination of the remains of polycyclic aromatic hydrocarbons with a flame ionization detector (FID) and HP-6890 column, was used to determine polycyclic aromatic hydrocarbon concentrations. For the analysis of polycyclic aromatic hydrocarbons in the extracts, a HP 6890 gas chromatograph equipped with a flame ionization detector and a capillary column. The carrier gas flow rate in the GC-ECD was $1.5 \mathrm{~mL} \mathrm{~min}^{-1}$. The dried temperature was about $200{ }^{\circ} \mathrm{C}$. The injection volume of extract was $2 \mu \mathrm{L}$. Chloride was analyzed by using a DIONEX ion chromatograph (IC), equipped with a 4-mm The IonPac AS14A anion-exchange column.

Sampled $7 \mathrm{~mL}$ polycyclic aromatic hydrocarbons solution (200 $\mu \mathrm{g} \mathrm{L}^{-1}$ ) were pretreated by the above described method, then detected by GC-FID and calculated the recovery of polycyclic aromatic hydrocarbons. Results showed that the recovery of polycyclic aromatic hydrocarbons was stabilized at the level of 90-95\%.

In headspace $\mathrm{GC}$ analysis, $25 \mathrm{~mL}$ of reaction mixture and $1 \mathrm{~mL}$ of $n$-chloropentane ( $\mathrm{PeCl}$, as internal standard for $\mathrm{CK}$ ) saturated solution were filled into a $43.0 \mathrm{~mL}$ vial, which was then immediately sealed with a thermo scientific mininert pushbutton valve. In turn, the sample filled vials were put into a water-bath with the temperature controlled at $70{ }^{\circ} \mathrm{C}$ for 30 min, allowing for complete volatilization of polycyclic aromatic hydrocarbons and $\mathrm{PeCl}$. Following this, a volume of $500 \mu \mathrm{L}$ of head-space gas mixture was withdrawn for GC analysis. The chloride was measured by IC analysis and samples were filtered through $0.45 \mu \mathrm{m}$ glass fiber filters to remove the sodium carbonate micro particles ${ }^{4,6}$.

\section{RESULTS AND DISCUSSION}

In general, peroxide can oxidize polycyclic aromatic hydrocarbons under acidic and alkaline conditions, but the oxidation efficiency is higher at lower $\mathrm{pH}$ value. Fig. 1 depicts the effect of initial $\mathrm{pH}$ on the oxidation of polycyclic aromatic hydrocarbon. Under the experimental conditions of [PAHs] $=1$ $\times 10^{-3} \mathrm{M},\left[2 \mathrm{Na}_{2} \mathrm{CO}_{3} \cdot 3 \mathrm{H}_{2} \mathrm{O}_{2}\right]=2 \times 10^{-3} \mathrm{M}$ and initial $\mathrm{pH}=5,6,7$, 8 and 9 , there was no significant difference for the oxidation ratios of polycyclic aromatic hydrocarbons. Hunkeler et al. ${ }^{6}$ have reported that $\mathrm{pH}$ did not affect polycyclic aromatic hydrocarbons oxidation by peroxide, but change the species and concentration of oxidation intermediates. They also found that $90 \%$ of carbon dioxide was produced at acidic $\mathrm{pH}$ and only about $60 \%$ was detected under alkaline conditions. In this study, although the initial pHs were 5, 6, 7, 8 and 9, after 60 min of reaction time, the final $\mathrm{pH}$ of the reaction mixtures were below 2.8 (Table-1). There is no significant difference in polycyclic aromatic hydrocarbons oxidation at different initial $\mathrm{pH}$ value.

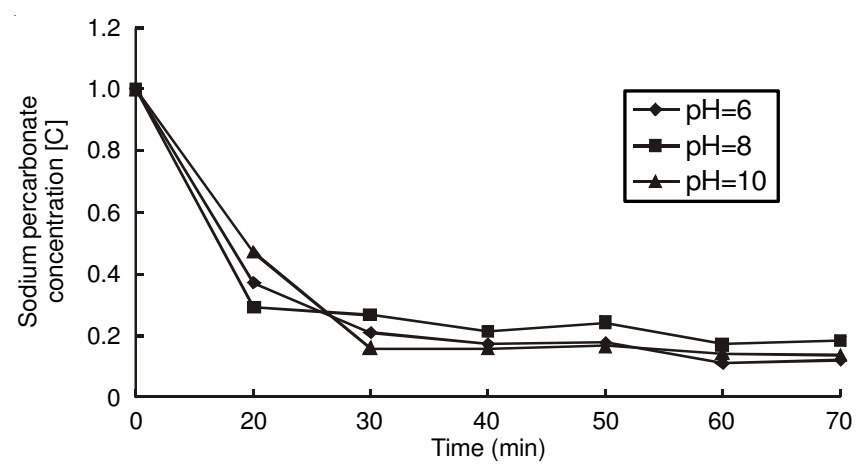

Fig. 1. Effect of initial $\mathrm{pH}$ on the oxidation of PAH. $[\mathrm{PAHs}]=1 \times 10^{-3} \mathrm{M}$, $\left.\left[2 \mathrm{Na}_{2} \mathrm{CO}_{3} \cdot 3 \mathrm{H}_{2} \mathrm{O}_{2}\right]=2 \times 10^{-3} \mathrm{M}\right)$

TABLE-1

VARIATION OF PH WITH TIME OF PAH OXIDATION RANGE

\begin{tabular}{cccccc}
\hline \multirow{2}{*}{$\begin{array}{c}\text { Time } \\
(\min )\end{array}$} & 5.00 & 6.0 & 7.00 & 8.0 & 9.00 \\
\cline { 2 - 6 } & 8.8 & 8.8 & 8.8 & 8.8 & 8.8 \\
5 & 8.7 & 8.8 & 8.8 & 8.8 & 8.8 \\
10 & 8.7 & 8.7 & 8.7 & 8.8 & 8.8 \\
20 & 8.7 & 8.7 & 8.7 & 8.7 & 8.7 \\
30 & 8.7 & 8.7 & 8.7 & 8.7 & 8.7 \\
60 & & & & & \\
\hline
\end{tabular}

Effect of $[\mathrm{PAHs}] /\left[2 \mathrm{Na}_{2} \mathrm{CO}_{3} \cdot 3 \mathrm{H}_{2} \mathrm{O}_{2}\right]$ reaction ratio: In these experiments, the initial polycyclic aromatic hydrocarbons concentration was kept at $1.0 \times 10^{-3} \mathrm{M}$. The ratios of [PAHs]/ $\left[2 \mathrm{Na}_{2} \mathrm{CO}_{3} \cdot 3 \mathrm{H}_{2} \mathrm{O}_{2}\right]$ were varied by changing the concentration of peroxide. Fig. 2 shows the effect of $[\mathrm{PAHs}] /\left[2 \mathrm{Na}_{2} \mathrm{CO}_{3} \cdot 3 \mathrm{H}_{2} \mathrm{O}_{2}\right]$ ratio on the oxidation of polycyclic aromatic hydrocarbons. When the ratios of $[\mathrm{PAHs}] /\left[2 \mathrm{Na}_{2} \mathrm{CO}_{3} \cdot 3 \mathrm{H}_{2} \mathrm{O}_{2}\right]$ were $2,1,0.5$ and 0.25 , then $70,45,20$ and $5 \%$ polycyclic aromatic hydrocarbons, respectively, were remaining in the reaction mixtures.

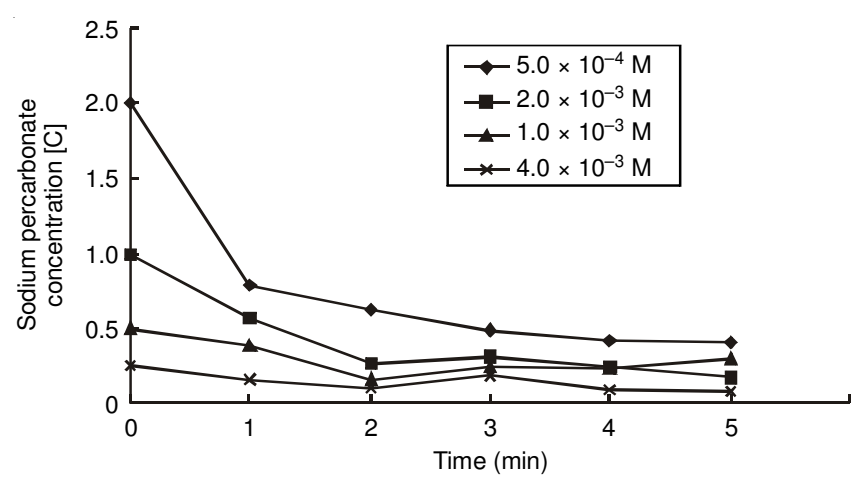

Fig. 2. Effect of $\left[2 \mathrm{Na}_{2} \mathrm{CO}_{3} \cdot 3 \mathrm{H}_{2} \mathrm{O}_{2}\right]$ on the oxidation of PAH at [PAHs] = $7 \times 10^{-4} \mathrm{M}$

Fig. 2 shows the results with $6 \times 10^{-4} \mathrm{M}$ initial polycyclic aromatic hydrocarbon concentration and the ratios of [PAH]/ $\left[2 \mathrm{Na}_{2} \mathrm{CO}_{3} \cdot 3 \mathrm{H}_{2} \mathrm{O}_{2}\right]$ were also $2,1,0.5$ and 0.25 . The remaining percentages of polycyclic aromatic hydrocarbons after $60 \mathrm{~min}$ of reaction were 70, 50, 20 and $5 \%$. By comparing Fig. 2 with Fig. 3, it can be illustrate that the oxidation of polycyclic aromatic hydrocarbon depended on the ratio of [PAHs]/ $\left[2 \mathrm{Na}_{2} \mathrm{CO}_{3} \cdot 3 \mathrm{H}_{2} \mathrm{O}_{2}\right]$ under the experimental conditions. The complete oxidation of polycyclic aromatic hydrocarbons occurred at ratios of $[\mathrm{PAH}] /\left[2 \mathrm{Na}_{2} \mathrm{CO}_{3} \cdot 3 \mathrm{H}_{2} \mathrm{O}_{2}\right]$ greater than 0.25 . In other words, the concentration of sodium percarbonate has to be four times higher than that of polycyclic aromatic 
TABLE-2

RELATIONSHIP BETWEEN INITIAL $\left[2 \mathrm{Na}_{2} \mathrm{CO}_{3} \cdot 3 \mathrm{H}_{2} \mathrm{O}_{2}\right.$ ] AND PAH OXIDATION RATE

\begin{tabular}{|c|c|c|c|c|c|}
\hline$[\mathrm{PAH}]\left(\times 10^{-4} \mathrm{M}\right)$ & {$\left[2 \mathrm{Na}_{2} \mathrm{CO}_{3} \cdot 3 \mathrm{H}_{2} \mathrm{O}_{2}\right]\left(\times 10^{-4} \mathrm{M}\right)$} & $\begin{array}{c}\text { Initial rate } \\
\left(\times 10^{-5} \mathrm{M} / \mathrm{min}\right) \\
\end{array}$ & {$[\mathrm{PAH}]\left(\times 10^{-4} \mathrm{M}\right)$} & $\begin{array}{c}{\left[2 \mathrm{Na}_{2} \mathrm{CO}_{3} \cdot 3 \mathrm{H}_{2} \mathrm{O}_{2}\right]} \\
\left(\times 10^{-4} \mathrm{M}\right)\end{array}$ & $\begin{array}{c}\text { Initial rate } \\
\left(\times 10^{-5} \mathrm{M} / \mathrm{min}\right) \\
\end{array}$ \\
\hline 10 & 40 & 14.3 & 6.0 & 24 & 8.05 \\
\hline 10 & 20 & 10.5 & 6.0 & 12 & 4.37 \\
\hline 10 & 10 & 7.22 & 6.0 & 6.0 & 3.37 \\
\hline 10 & 5.0 & 3.62 & 6.0 & 3.0 & 1.85 \\
\hline 8.0 & 32 & 11.4 & 4.0 & 16 & 4.18 \\
\hline 8.0 & 16 & 7.33 & 4.0 & 8.0 & 2.30 \\
\hline 8.0 & 8.0 & 4.64 & 4.0 & 4.0 & 2.34 \\
\hline 8.0 & 4.0 & 1.22 & 4.0 & 2.0 & 1.94 \\
\hline
\end{tabular}

hydrocarbons. According to one mole of polycyclic aromatic hydrocarbon needs $2 \mathrm{~mol}$ of sodium percarbonate is complete oxidation. However, from the results obtained in Figs. 2 and 3 , only $50-60 \%$ of polycyclic aromatic hydrocarbons was oxidized, as shown in Table-1. It is assumed that the oxidation intermediates competed with polycyclic aromatic hydrocarbons in capturing the sodium percarbonate molecules, leading to the inhibition of polycyclic aromatic hydrocarbons oxidation. The removal ratio of polycyclic aromatic hydrocarbons was about $95 \%$, if the reaction was extended to $60 \mathrm{~min}$. In this way, most of the polycyclic aromatic hydrocarbons molecules were decomposed initially. With increasing reaction time, the concentration of oxidation intermediates increased gradually, which may compete with polycyclic aromatic hydrocarbons in capturing $2 \mathrm{Na}_{2} \mathrm{CO}_{3} \cdot 3 \mathrm{H}_{2} \mathrm{O}_{2} \cdot \mathrm{CO}_{2}$ is generated from the reaction of polycyclic aromatic hydrocarbons oxidation and $\mathrm{H}^{+}$is then produced, leading to the reduction of $\mathrm{pH}$. Peroxide can also react with water molecules to release $\mathrm{OH}^{-}$, but this is very slow, compared with the amount of $\mathrm{H}^{+}$produced in polycyclic aromatic hydrocarbons oxidation.

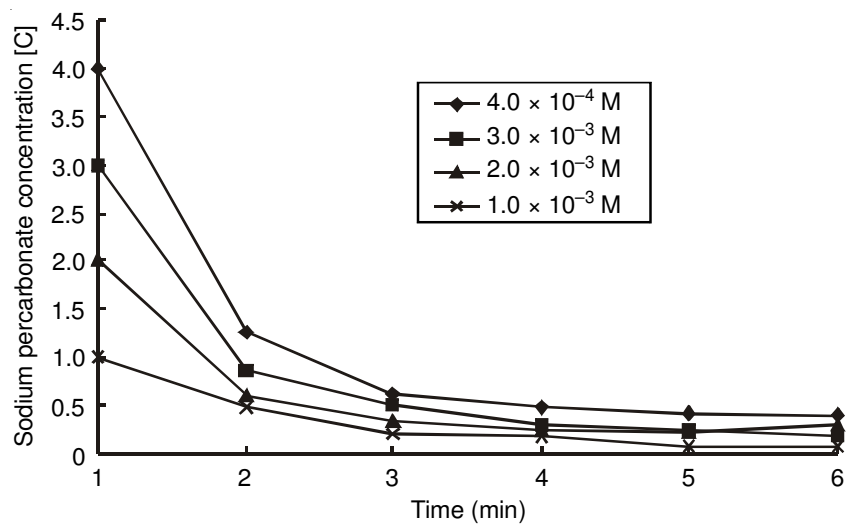

Fig. 3. Effect of $\left[2 \mathrm{Na}_{2} \mathrm{CO}_{3} \cdot 3 \mathrm{H}_{2} \mathrm{O}_{2}\right]$ on the oxidation of PAHs at [PAHs]

Effect of sodium percarbonate on the initial oxidation rate: In Table-2, the initial rates of polycyclic aromatic hydrocarbons oxidation at different molar ratios of [PAHs]/ $\left[2 \mathrm{Na}_{2} \mathrm{CO}_{3} \cdot 3 \mathrm{H}_{2} \mathrm{O}_{2}\right]$, namely $2,1,0.5$ and 0.25 , are listed. In order to explore the effect of $\left[2 \mathrm{Na}_{2} \mathrm{CO}_{3} \cdot 3 \mathrm{H}_{2} \mathrm{O}_{2}\right]$ on the reaction rate, these initial rates of polycyclic aromatic hydrocarbons oxidation were calculated. Fig. 4 illustrates the relationship of initial oxidation rate and initial $\left[2 \mathrm{Na}_{2} \mathrm{CO}_{3} \cdot 3 \mathrm{H}_{2} \mathrm{O}_{2}\right]$. Results show that the initial rate increased with increasing $\left[2 \mathrm{Na}_{2} \mathrm{CO}_{3} \cdot 3 \mathrm{H}_{2} \mathrm{O}_{2}\right]$ and [PAHs]. As shown in Fig. 2, $70 \%$ of polycyclic aromatic hydrocarbons was removed in the first 5 min of reaction time,

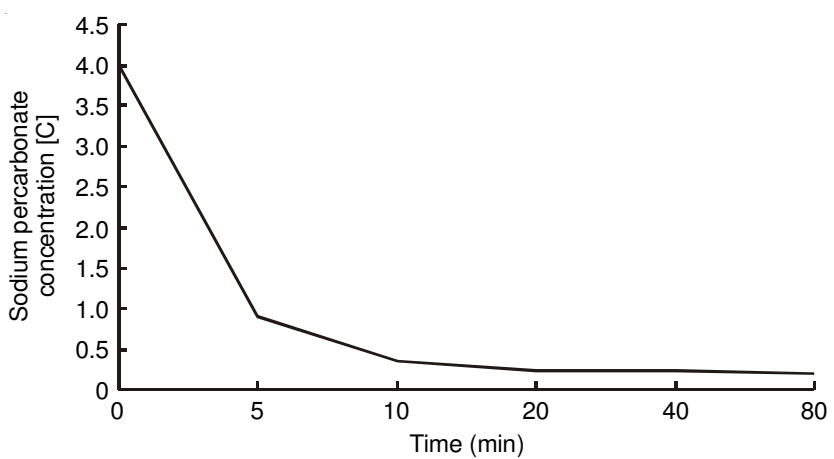

Fig. 4. Effect of $\left[2 \mathrm{Na}_{2} \mathrm{CO}_{3} \cdot 3 \mathrm{H}_{2} \mathrm{O}_{2}\right]$ on the oxidation of PAHs at [PAHs], initial PAHs concentrationwas $4.0 \times 10^{-3} \mathrm{M}$

when the concentration of peroxide was $4.0 \times 10^{-3} \mathrm{M}$. The removal ratio of polycyclic aromatic hydrocarbons was about $95 \%$, if the reaction was extended to $60 \mathrm{~min}$. In this way, most of the polycyclic aromatic hydrocarbons molecules were decomposed initially. With increasing reaction time, the concentration of oxidation intermediates increased gradually, which may compete with polycyclic aromatic hydrocarbons in capturing $2 \mathrm{Na}_{2} \mathrm{CO}_{3} \cdot 3 \mathrm{H}_{2} \mathrm{O}_{2}$. De-chlorination of polycyclic aromatic hydrocarbons in general, the toxicity of organic chemicals increases with their number of chlorine atoms. Therefore, removing the chlorine from the chemical structure can initiate the reduction of toxicity. In this study, chloride ions were detected during the oxidation reaction. Theoretically, $1 \mathrm{M}$ of polycyclic aromatic hydrocarbons, at most, releases three moles of chloride ions. In this case, the ratio of $\left[\mathrm{Cl}^{-}\right] /$ 3 [PAHs] was applied to evaluate the dechlorination reaction. When $95 \%$ of polycyclic aromatic hydrocarbons was decomposed, only $80 \%$ of chloride ions were released into the reaction mixture; $20 \%$ of chlorine still remained in the organics. Hunkeler et $a l .{ }^{6}$. reported on complete dechlorination of polycyclic aromatic hydrocarbon at a $[\mathrm{PAH}] /\left[2 \mathrm{Na}_{2} \mathrm{CO}_{3} \cdot 3 \mathrm{H}_{2} \mathrm{O}_{2}\right]$ ratio of 0.06 . However, only 0.25 was applied in the present study.

\section{Conclusion}

Experiments of polycyclic aromatic hydrocarbons oxidation by sodium percarbonate were carried out in this study. The initial rate of polycyclic aromatic hydrocarbons oxidation almost increased linearly with increasing the initial concentration of polycyclic aromatic hydrocarbons. The factors, $\mathrm{pH}$ and ratio of [PAHs]/[2 $\left.\mathrm{Na}_{2} \mathrm{CO}_{3} \cdot 3 \mathrm{H}_{2} \mathrm{O}_{2}\right]$, affecting the reaction have been explored. Even the theoretical dosage of [PAH]/ $\left[2 \mathrm{Na}_{2} \mathrm{CO}_{3} \cdot 3 \mathrm{H}_{2} \mathrm{O}_{2}\right]$ is 0.5 for complete degradation of polycyclic aromatic hydrocarbons, it still needed, at least, 4 mol of 
$2 \mathrm{Na}_{2} \mathrm{CO}_{3} \cdot 3 \mathrm{H}_{2} \mathrm{O}_{2}$ to decompose this chemical. This indicates that oxidation intermediates and the parent polycyclic aromatic hydrocarbons competed with sodium percarbonate molecules. Initial $\mathrm{pH}$ has no significant effect on the [PAHs] oxidation, because hydrogen ions were released during the period of oxidation reaction.

\section{ACKNOWLEDGEMENTS}

This work has been supported by the Education Office of Heilongjiang Province Science and Technology Research Project funding (Project Number: 12521573).

\section{REFERENCES}

1. E. Arctander and P. Bardos, Available: http://www. Clarin et al. [20 April 2005].

2. M. Eriksson, E. Soderstern, Z. Yu and W.W.D.G. Mohn, Appl. Environ. Microbiol., 69, 275 (2003)

3. A.-S. Allard, M. Remberger and A.H. Neilson, Int. Biodeter. Biodegrad., 46. 43 (2006)

4. K.-C. Huang, G.E. Hoag, P. Chheda, B.A. Woody and G.M. Dobbs, J. Hazard. Mater, 87, 155 (2001).

5. A.S. Hasson and I.W.M. Smith, J. Phys. Chem. A, 103, 2031 (1999).

6. D. Hunkeler, R. Aravena, B.L. Parker, J.A. Cherry and X. Diao, Lab. Field Stud. Environ. Sci. Technol., 37, 798 (2003).

7. T.T. Tsai, C.M. Kao, T.Y. Yeh, S.H. Liang and H.Y. Chien, J. Hazard. Mater, 161, 111 (2009). 